\title{
Ayakta küçük parmak deformiteleri
}

\author{
Lesser toe deformities
}

\author{
Umur Aydoğan \\ Milton S. Hershey Medical Center, Division of Foot and Ankle Surgery, Penn State University, Pennsylvannia, USA
}

\begin{abstract}
Küçük parmak deformiteleri, travmaları dışarıda tutarsak, ayak patolojileri arasında en sık karşımıza çıkan sorunları içerir. Her ne kadar ortopedik cerrahlar tarafından iyi bilindiği zannedilse de çoğu sorun dar kalıplarla, sınırlı koruyucu veya cerrahi teknikler ile tedavi edilmeye çalışılır. Bu deformitelerin en önemli nedeni yanlış ayakkabı giyimidir. Bu nedenle sıklıkla ileri evrede görülen ve cerrahi gerektiren bu sorunların doğru ayakkabı seçimi de dahil koruyucu tedavisi daha fazla önem taşımaktadır. Genelde tüm küçük parmak deformiteleri çekiç parmak veya nasır olarak adlandırıldığı ve bu nedenle yanlış tedavi edilebildiği için özellikle tanı çok önem taşımaktadır. Bu derlemede sık karşılaşılan küçük parmak deformitelerinin tanı ve tedavisi son gelişen teknikler ışığında anlatılmaya çalışılacaktır.
\end{abstract}

Anahtar sözcükler: ayak parmakları; ayak deformiteleri; kallus; metatarsalji; instabilite, eklem

Ayakta küçük parmak deformiteleri, ayak cerrahisi ile yakından ilgilenen ortopedi uzmanlarının en sık karşılaştıkları sorunlardan biridir. Yurt dışında podiatrist olarak adlandırılan, ayak bakımı ve cerrahi olmayan ayak sorunlarının tedavisi ile uğraşan uzmanların ülkemizde olmaması, ortopedi uzmanlarımızı bu sorunlarla ancak ileri safhalarında karşı karşıya bırakmakta ve çoğu zaman yalnızca cerrahi tedavi ile sonuç alınabilmektedir. Ayak ve ayak bileği cerrahisinin ilgi alanı içindeki tüm konular gibi, küçük parmak deformitelerinin tedavisinde de son yıllarda birçok gelişme yaşanmaktadır. En son Coughlin tarafindan popülarize edilen plantar plate tamiri gibi cerrahi tekniklerle birlikte, şu ana kadar başka türlü tedavi edilegelen sorunların yeni tedavi algoritmaları ortaya çıkmaktadır. ${ }^{[1]}$

Her ne kadar bazı küçük parmak deformitelerinin oluşumu travmatik, nöromusküler, dejenetatif veya konjenital nedenlere bağlanabilirse de, ayakta küçük parmak deformitelerinin ortaya çıkmasındaki en
Apart from traumas, lesser toe deformities consist the most common problems among the foot pathologies. Although it is supposed that orthopedic surgeons have a good knowledge on these, they are usually treated with conservative and surgical techniques with limited and narrow patterns. The most important cause of these deformities is false shoe wear. Thus, conservative treatment of these problems which are usually encountered in the late stage and need surgical treatment carry great importance, including correct shoe selection. Diagnosis carries much importance, since lesser toe deformities are usually erroneously named as hammer toe or callus and could be treated improperly. In this review, diagnosis and treatment of the common lesser toe deformities will be explained in the light of lately developed techniques.

Key words: toes; foot deformities; callus; metatarsalgia; instability, joint

büyük neden yanlış ayakkabı giyimidir. Ülkemizde son yıllarda rahat ve anatomik ayakkabı giyimi konusunda bazı firmaların özelleşmesi ve yeni ürünler sunması sayesinde halkımız daha bilinçlenmiş olsa da, bu sorun etiyolojide hala birinci sırayı almaktadır.

Bu derlemede küçük parmak deformitelerinin konservatif ve cerrahi tedavileri konularına değinilecek ve bu sorunların daha rahat anlaşılması amacı ile fonksiyonel anatomi ve hastalık oluşum mekanizmalarına değinilecektir. Sıklıkla karşımıza çıkan pençe parmak, çekiç parmak, tokmak (mallet) parmak, metatarsofalangeal instabilite, bunionet deformitesi ve parmak nasırları alt konu başıkları olarak seçilmiştir.

\section{TANIMLAMALAR VE ETIYOLOJi}

Pratikte ayak küçük parmak deformiteleri doktorlar tarafından genellikle çekiç parmak veya metatarsalji olarak adlandırılır. Ancak metatarsalji bir tanı değil,

- Illetişim adresi: Umur Aydoğan, MD, Penn State University, Milton S. Hershey Medical Center, Bone and Joint Institute, 30 Hope Drive, 17033 , Hershey, Pennsylvannia, USA. Tel: 800-243-1455/717-531-5638 e-posta: uaydogan@hmc.psu.edu

- Geliș tarihi: 16 Eylül 2013 Kabul tarihi: 24 Ekim 2013 
ayak önünde gelişen taban ağrısı için kullanılan bir genel ifade, bir tanımlamadır. Çekiç parmak ise küçük parmağın kıvrılması ile sonuçlanan tüm deformiteleri tanımlamak için kullanılagelmiştir. Uygun tedaviyi sunabilmek için tedavi eden doktorun değişik deformiteleri ayırt edebilmesi ve bu deformiteleri meydana getiren değişik etiyolojik etmenleri bilmesi gereklidir. Ayak küçük parmak deformiteleri aşağıdaki şekilde genel bir sınıflandırmaya tabi tutulabilir. ${ }^{[2]}$

- Hareketli: pasif olarak düzeltilebilen; genellikle kısa veya orta zamanlı bir süredir devam eden.

- Sabit: Pasif olarak düzeltilemeyen; uzun süredir devam eden.

\section{KÜÇÜK PARMAK DEFORMITELERINDE CERRAHI OLMAYAN TEDAVI}

Küçük parmak deformitelerinin semptomatik tedavisi cerrahi olmayan tedavi yöntemleri ile sağlanabilmektedir. Kemikte deformite yoksa veya çok erken evrede ise, başarı şansı düşük olsa bile bu yöntemler denenmelidir. Burada amaç deformitenin tamamen tedavisi değil, hastanın ağrısız bir şekilde ve yaşadığı sorunda artış olmaksızın yaşayabilmesidir. Tedavinin en önemli basamağı ağrılı ve deformiteli bölgedeki basıyı azaltmaktır.

Çekiç, pençe veya tokmak parmak gibi deformitelerde dorsal bası daha derin ön ayak ölçülerine sahip ayakkabılar ile sağlanabilir. Geniş ayak önüne sahip ayakkabılar ise semptomatik bunionet ve metatarsofalangeal (MTF) eklem instabilitelerinde etkili olmaktadır. Geniş ayakkabılar aynı zamanda yumuşak nasır gibi parmak arası basının önem kazandığı durumların tedavisinde de etkilidir. Bununla beraber, parmak arası basının ve sürtünmenin azaltılmasını sağlayan parmak ayraçları, silikon makaralar veya yün tamponlar deformite oluşumunun önlenmesinde ve semptomatik tedavide önem kazanmaktadır.

MTF eklem instabilitesi veya çekiç parmakta parmağı plantar fleksiyona zorlayan fabrikasyon veya özel yapım cihazlar, kalıcı tedavi sağlamazlarsa da semptomatik tedavide yerleri vardır. Burada hasta uyumu önem taşımaktadır. Tokmak parmakta, distal parmak basıncını azaltmaya yarayan parmak altı yastıkları yararlı olmaktadır. Plantar ağrı için ise daha sert ve salınım yapmaya izin veren "beşik taban" (rocker-bottom) ayakkabılar kullanılabilir.

Eğer hastada MTF eklem instabilitesi veya çıkı̆̆ı varsa, sadece ayakkabı değişikliği yeterli olmaz. Bu hastalarda özellikle plantar basıncı azaltan metatarsal pedler etkilidir. Burada önemli olan pedi uygun noktaya yerleştirebilmektir. Özellikle piyasada satılan kişiye özel olmayan pedler ayakkabı içerisinde kayıp özellikle distale doğru yer değiştirmekte ve ağııı MTF eklem altına kaymaktadır. Bu durum sonrasında hastanın ağrısı azalacağına artmaktadır. Yazarın klinik deneyiminde, eğer hastaya ped verilecekse altı yapışkanlı pedler önerilmekte veya uzun süreli kullanım söz konusu ise kişiye özel tabanlık yapılması planlanmaktadır.

Cerrahi olmayan yöntemler hastaların özellikle akut yakınmalarının azaltılmasında etkilidir, ancak ne yazık ki deformitenin düzeltilmesinde etkileri yoktur. Bu nedenle deformitesi olan, özellikle sabit deformitesi bulunan hastalar zaman içerisinde cerrahi tedaviye gerek duyabilmektedir.

\section{Çekiç parmak}

Çekiç parmak deformitesi ayakta en sıklıkla tedavi edilen küçük parmak deformitesidir. Çekiç parmakta MTF eklem ektansiyonda, proksimal interfalangeal (PIF) eklem fleksiyonda, distal interfalangeal (DiF) eklem ise ektansiyondadır. Genellikle çekiç parmak oluşumu altında sıkı ayakkabı giyimi sonucu oluşan basının parmağı ekstansiyona getirmesi etkindir. Deformitenin doğal düzleme getirilip getirilememesi hareketli veya sabit olarak adlandırılmasında etkilidir (Şekil 1).

\section{Tedavi}

Hareketli: Her ne kadar hastalar bu durumda nadiren cerraha gitmeye razı olsalar da, bükülebilir çekiç parmak deformitesi genellikle kollateral yumuşak doku gevşetme veya fleksörden ektansöre tendon transfer tekniği ile düzeltilebilmektedir (Girdlestone-Taylor tekniği):

- Flexor digitorum longus (FDL) tendonunun distal insersiyondan ayrilıp proksimal falanksın

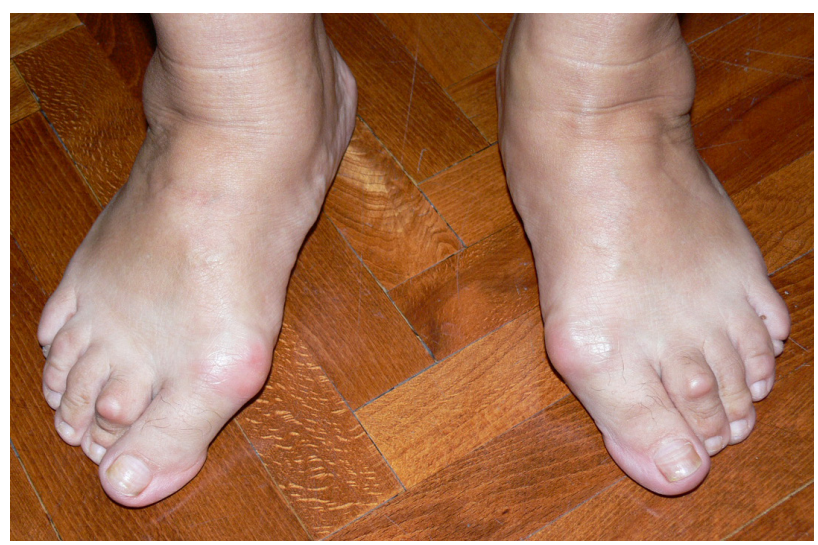

Şekil 1. Bilateral erken evre HV ile beraber görülen 2. sabit çekiç parmak ve 3. Bükülebilir çekiç parmak olgusu. Sabit eklem dorsalinde sert nasırlaşma vardır. 
dorsaline transferini amaçlar. Bu transfer ile MTF ve DiF eklem ekstansiyonu ile PiF eklemin fleksiyon deformitelerinin dengelenmesi amaçlanmıştır.

- Bu teknikte FDL tendonu DiF eklem hizasında plantardan perkütan olarak kesilir. Bu esnada parmak hiperekstansiyona alınır ve tendonun proksimale kaçması sağlanır.

- Parmak proksimal fleksiyon cilt katlantısı hizasından plantar $5 \mathrm{~mm}$ kesi sonrası fleksör tendon kılıfi görülür. FDL daha volarde ve çift slipli olarak tespit edilir ve daha önce distalden kesilmiş olan tendon buradan dışarı alınır ve tendon sliplerinden $2 \mathrm{~cm}$ boyunca ikiye ayrilır.

- Cilt MTF eklem dorsalinden kesilir ve bir ince klemp yardımı ile eklem dışından plantara inilerek slipler teker teker bulunur ve dorsale alınır. Bu esnada nörovasküler yapıların sliplerin altında sıkışmamasına dikkat edilir.

- Ayak bileği hafif plantar fleksiyonda ve MTF eklem 5 derece plantar fleksiyonda olacak şekilde dorsale alınan tendon slipleri birbirine ve MTF eklem kapsülüne dikilir.

- Parmak 5 derece plantar fleksiyonda bant yardımı ile sabitlenir.

Bazen çekiç parmak ile beraber MTF eklem seviyesinde hafif bir ekstansiyon kontraktürü görülebilir; bu durumda dorsal MTF kapsülotomisi ve extensor digitorum longus (EDL) tendonunun $\mathrm{Z}$ uzatması ile deformite düzeltilebilir.

Sabit: Sabit çekiç parmak deformiteleri bükülebilir deformitelere nazaran sadece yumuşak cerrahisi ile düzeltilemez. Bunun yerine PiF eklem artrodezi veya DuVries rezeksiyon artroplastisi ile sonuç alınabilir.

Yazar Görüşü: Rezeksiyon artroplastisi sonucunda son yıllarda ağrılı kaynamama, kalıcı şişlik ve nüksler bildirilmiştir. Bu nedenle yazar iP artrodez (proksimal falanks başı eksizyonu) tekniğini uygulamaktadır.

Son yıllarda implantlardaki gelişmeye bağlı olarak daha önce sadece $K$ teli kullanılarak yapılan geçici fiksasyon için günümüzde özel intramedüller iP eklem vidaları kullanılmaya başlanmıştır. Bu implantlar hastayı ameliyat sonrası dönemde K teli çıkartılmasından veya olası kaynamama ve enfeksiyondan kurtarmayı ve kullanılan değişik açılardaki fleksiyon miktarı veren vidalar yardımı ile fizyolojik iP eklem fleksiyonu sağlamayı amaçlamaktadırlar. Bu implantlardaki en büyük sorun ise implantların çıkarılması gerektiğinde hem çıkarılmalarının çok zor olması hem de çıkarılma sonrası greftlemeyi gerektiren büyük bir kemik boşluk bırakmalarıdır.
Bazen artrodez veya rezeksiyon artroplastisi sonrası DiF eklemde fleksiyon deformitesi gelişebilmektedir; bu nedenle hastaya distal FDL perkütan tenotomi eklenmesi gerekebilir. Yine hastada MTF eklemde ekstansiyon kontraktürü varsa EDL Z uzatma, MTF dorsal kapsülotomi ve/veya kollateral gevşetme eklenebilir.

Bazen çekiç parmağa ek olarak MTF eklem instabilitesi ve şiddetli MTF ekstansiyon kontraktürü görülebilir. Bu sorunların da, aynı seansta ileride anlatılacağı üzere, cerrahi olarak tedavisi gereklidir.

\section{Pençe parmak}

Çekiç parmaktan farklı olarak pençe parmak deformitesinde MTF eklem ekstansiyonda iken hem PiF hem de DiF eklem fleksiyondadır. Eldeki benzer deformiteyle eşdeğer bir etiyoloji hakimdir ve intrensek negatif kas çekim dengesizliği esas etiyolojik etmendir. Her ne kadar yanlış ayakkabı giyimi hala en önemli etiyolojik etmen olarak düşünülse de hastada var olan ve kas dengesizliğine yol açan bir nörolojik hastalık bu sorunun çıkmasında etkili olmaktadır. Bu durum özellikle problemin her iki ayakta da görülmesini açıklar. İntrensek negatif bir MTF eklemde stabilizasyonu sağlayan lumbrikal ve interosseöz kasların az çalışması sonucu ekstansör kaslar MTF eklem düzeyinde, fleksör kaslar ise PiF ve DiF eklem düzeyinde güçlü hale gelmekte ve deformitenin oluşmasını sağlamaktadır. Bu konunun derinlemesine anlaşılabilmesi için Sarrafian tarafından yazılmış olan ayak anatomisinin okunması önerilir. ${ }^{[3]}$

Her ne kadar çekiç parmak ve pençe parmak doktorlar tarafından aynı deformitenin tanımlamasında sıklıkla kullanılsa da, aslında bu iki patolojinin ayrı ayrı değerlendirilmesi, tanısının konması ve farklı tedaviler uygulanması gerekli olabilmektedir.

Hareketli: Hareketli pençe parmağın tedavisi hareketli çekiç parmağın tedavisi ile benzerdir. Pençe parmakta MTF eklemdeki ek deformiteler daha fazla olduğu için sıklıkla yumuşak doku gevşetmelerine (dorsal kapsülotomi, EDL Z uzatma ve kollateral gevşetme vb.) ihtiyaç duyulur. Bazen de DiF eklem fleksiyon kontraktürünü düzeltmek amacı ile perkütan FDL tenotomisi uygulanabilir.

Sabit: Yine benzer olarak sabit pençe parmak deformitesinin cerrahisi tedavisi de sabit çekiç parmak tedavisi ile benzerlik gösterir; ancak, bu deformite çekiç parmağa göre daha ileri kontraktürler içerdiğinden, ek yumuşak doku gevşetme veya metatars kısaltmaya daha sık olarak başvurulur. Geleneksel DuVries metatars başı artroplastisi günümüzde yerini Weil metatars oblik kısaltma osteotomisine bırakmıştır. 
- Öncelikle dorsal kesiyle MTF ekleme ulaşılır ve yukarıda bahsedilen yumuşak doku gevşetmeler uygulanır.

- EDL tendonuna Z uzatma uygulanır. Yazarın tercihine göre extensor digitorum brevis (EDB) tenotomize edilir veya $Z$ uzatma uygulanır. Yazar kendi pratiğinde, yapışmayı en aza indirmek amacı ile EDB tendonuna dokunmamaktadır.

- Metatars başı ortaya konur ve sagittal motorlu kesici ve ince bıçak yardımı ile oblik bir osteotomi uygulanır. Osteotomi planı metatarsa 20 derece açı ile uygulanır. Osteotomi tamamlandığında metatars başı kendiliğinden 2-3 mm kadar proksimale kayar. Bazen bu kayma yeterlidir; bazen de floroskopi kontrolünde metatarsal parabolü bozmadan, el aletleri yardımı ile ek 1-2 mm kayma sağlanır.

- Osteotomi ufak bir vida yardımı ile metatars başı rotasyona itilmeden sabitlenir.

- Son olarak, kısaltma sonrası ortaya çıkan kemik parça kesilir.

Weil osteotomisinde püf noktalar (yazar görüşü): Weil osteotomisi her ne kadar çok etkili bir osteotomi olsa da uygulamada çok kolay değildir. Proksimale kayma eklemde dekompresyona yol açsa da metatars başının plantara yaptığı basıncın azalmasını sağlamak için osteotominin iki bıçak üst üste konularak yapılması veya dorsal bir üçgen çıkartılarak metatars başında dorsifleksiyon sağlanması gerekebilir. Yazar, dorsalden üçgen çıkarma tekniğini tercih etmektedir.
Aşırı kısaltmalardan kaçınmak gerekir, bu tür kısaltmalar sonucunda eklem stabilitesi kaybolup yüzen parmak (floppy toe) deformitesi gelişebilir. Weil osteotomisinin yazara göre en büyük problemi intraartiküler bir osteotomi olması ve sonrasında sıklıkla eklem kontraktürlerine ve eklem hareket kaybına yol açmasıdır. Bu nedenlerden ötürü yazar son yıllarda Weil osteotomisinden giderek uzaklaşmakta ve distal metatarsal şaft veya proksimal metatars basisinden yapılan oblik kısaltma osteotomilerini daha fazla tercih etmektedir (Şekil 2).

\section{Tokmak parmak}

Her ne kadar isim olarak Türkçe karşıı̆ğı tam anlamını ifade etmese de tokmak parmak nötral MTF ve PiF eklemle beraber görülen DiF eklem fleksiyon deformitesini tanımlamaktadır. Elde de benzer deformiteler görülür; ancak eldeki, travmatik etiyolojiye nazaran idiopatik veya kötü ayakkabı (özellikle uzun 2. ve 3. parmağı olan kişilerde kişinin başparmağının uzunluğuna göre ayakkabı seçmesi sonucu uzun parmakların ayakkabı ucuna vurması sonucu) kullanımı sonucu ortaya çıkması ile farklılık göstermektedir.

Hareketli: Hareketli bir tokmak parmak deformitesi perkütan FDL tenotomisi ile kolayca tedavi edilebilir. Tenotomi sonrasında parmağı bir K teli yardımı ile en az üç hafta ekstansiyonda korumak gereklidir.

Sabit: Sabit bir tokmak parmak tedavisinde DiF eklem rezeksiyon artroplastisi uygulanabilse de DiF ekleminin artrodezi en güvenilir seçenektir. Sıklıkla buna ek olarak kaynamaya engel olacağı düşüncesi ile FDL perkütan tenotomisi de bu işleme eklenir.
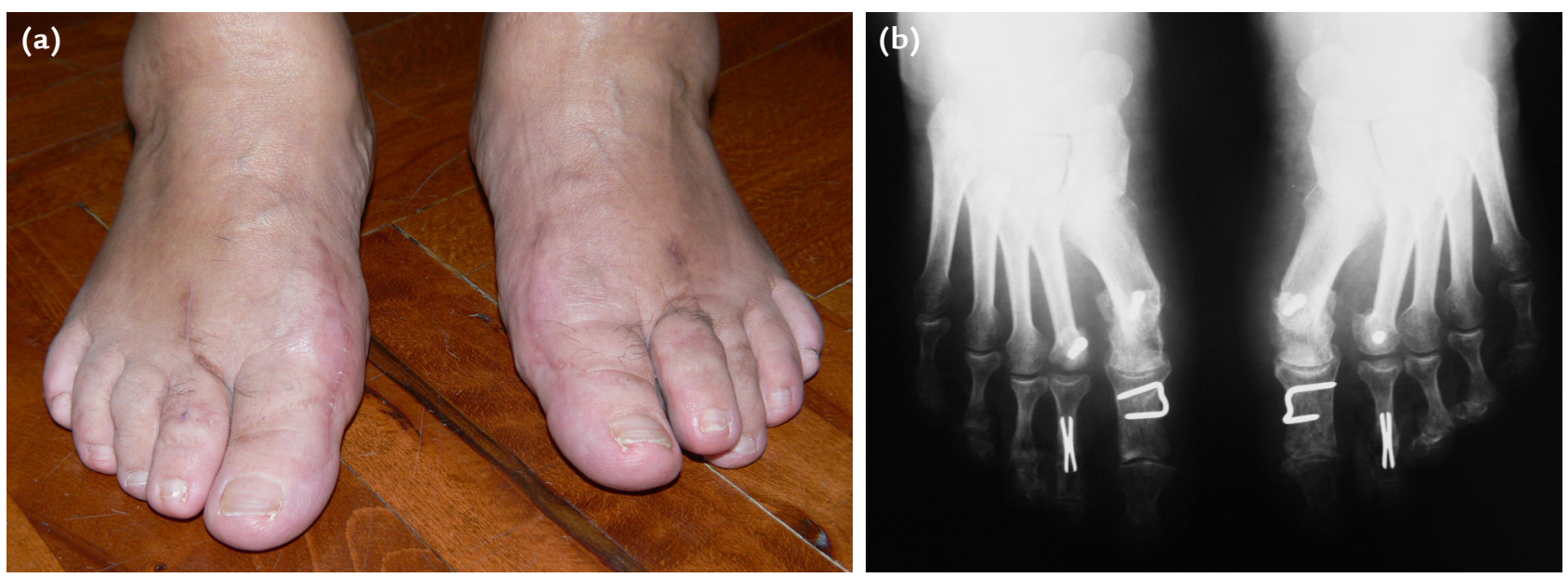

Şekil 2. a, b. Şekil 1'de görülen hastanın ameliyat sonrası görüntüsü ve AP ayak grafisi. HV için başarılı bir Chevron osteotomisi ve Akin osteotomisi uygulanmış ve 2. parmağa yer açılmıştır. 2. Parmak için yumusak doku gevşetme ve Weil osteotomisi ile beraber intramedüller implant yardımı ile PiF eklem artrodezi sağlanmıştır; ancak sol tarafta görüleceği üzere hastada MTF eklem dorsifleksyon deformitesi kalmıştır. Bunun birincil nedeni ameliyat sonrası gelişen yapışıklıklardır. 


\section{MTF eklem instabilitesi}

Son yıllarda giderek artan düzeyde tanı alması nedeni ile nispeten popüler bir konu olarak değerlendirebileceğimiz MTF eklem instabilitesi tüm ayak MTF eklemlerinde meydana gelebilir; ancak, sıklık sırası olarak 2., 3. ve 4. MTF eklemler gelir. Bu sorunun oluşmasında kötü ayakkabı giyimi yine baş etken iken, tekrarlayan stres ve travma veya eklem stabilitesini sağlayan yapıların işlevsiz hale gelmesini sağlayan romatoid artrit gibi romatizmal hastalıklar diğer etken mekanizmalar olarak karşımıza çıkar (Şekil 3).

MTF instabilitesi eklemin pasif stabilizatörlerinin (eklem kapsülü, kollateral bağlar vb.) güçsüzleşmesi sonucunda aktif stabilizatörlerin (kas ve tendon yapıların) etkin hale gelmesi sonucu ortaya çıkmaktadır. Bunun sonucu olarak ekstrensik ve intrensek kaslar ekleme bu stabilizatörler çalışmadan etki ettiği için deformite ortaya çıkar. Deformite genelde ekleme aşırı yük binmesi sonucu sinovit evresi ve şişlik ile başlar. ilerleyen evrelerde önce MTF eklemde dorsifleksiyon deformitesi, sonrasında ise eklemin dorsal subluksasyonu veya tam çıkığı görülebilir.

Bazen sadece kollateral bağların (sıklıkla lateral kollaterallerin) gücünü kaybetmesi sonucu eklemde koronal düzeyde bir instabilite gelişir ve parmaklar arası

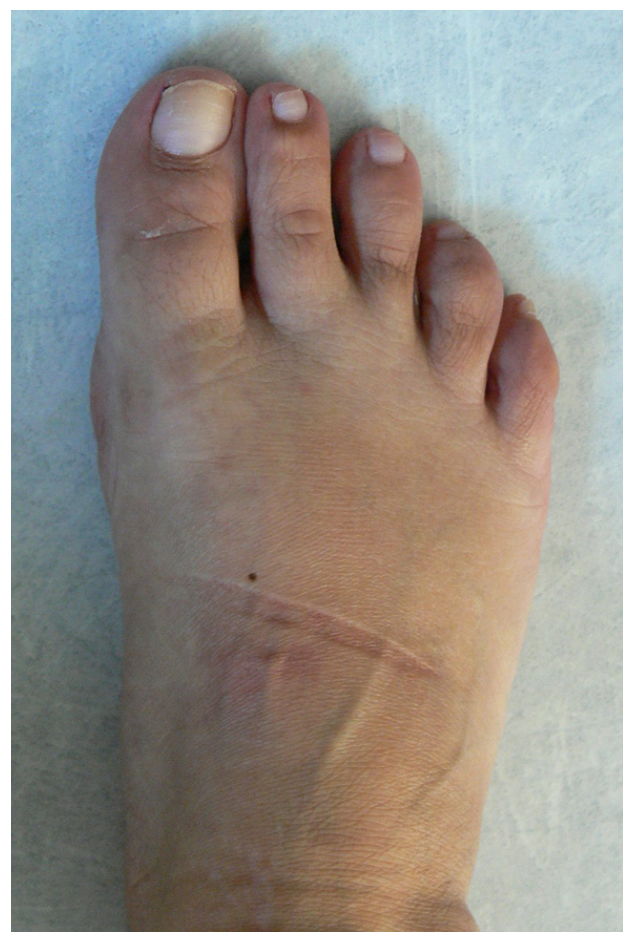

Şekil 3. İkinci MTF eklem hafif dorsal subluksasyonu ve koronal planda mediyale deviyasyonu ile sonuçlanan bir MTF eklem instabilte olgusu. açılır. Soruna son yıllarda daha fazla üzerine değinildiği üzere, eğer plantar plate yırtılması veya güçsüzleşmesi ile beraber dorsal açılanma eklenirse multiplanar instabilite de diyebileceğimiz ve üst üste binmiş parmak (cross-over toe) diye adlandırabileceğimiz deformite ortaya çıkar. Pratikte hastaların doktora en sık gittiği evre bu evredir ve kesin cerrahi tedavi gerektirir (Şekil 4).

Üst üste binmiş parmak deformitesinin daha az sıklıkla görülen diğer bir oluş mekanizması da hastada halluks valgus (HV) geliş̧mesi sonrası 2. MTF eklemin üzerine aşırı yük binmesidir. Bu gelişme sonucu 1. parmak 2. MTF eklemi sürekli sıkıştıracak, kendine yeterli boşluğu bulamayan 2. parmak ligamanları ve plantar plate'i de bu strese dayanamayıp gevşeyip yırtılacak ve deformite gelişecektir.

MTF eklem instabilite oluşumunda eklem üzerine aşırı yük binmesine yol açan diğer etkenler aşağıdaki gibi sıralanabilir:

- Uzun 2. veya 3. metatars

- Birinci metatarsın doğuştan veya iyatrojenik kısalığı

- Ön tarafi dar ayakkabı giyimi

Sinovit evresi: MTF eklem instabilitesindeki birinci evre olan sinovit evresinde, eğer izole bir problem

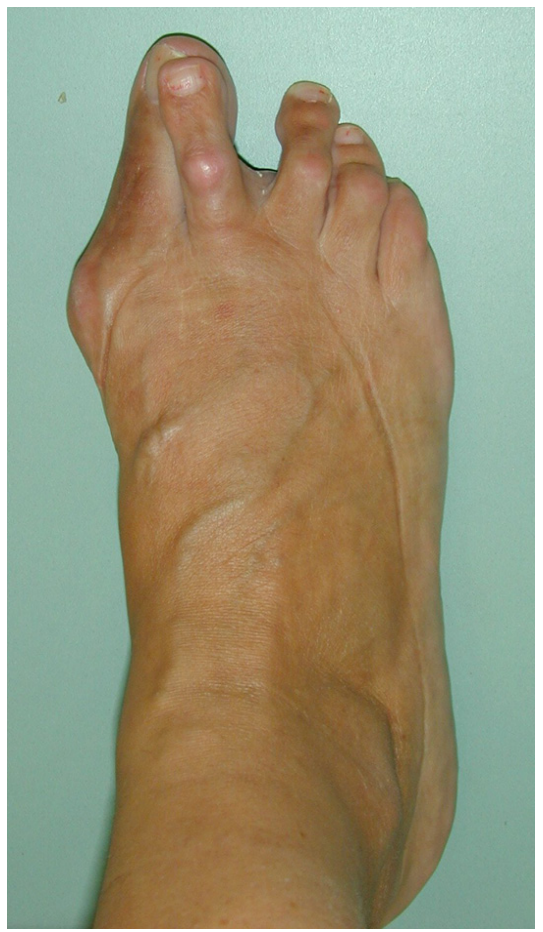

Şekil 4. İleri düzey bir üst üste binmiş parmak (cross-over toe) deformite olgusu. 
olarak karşımıza çıkarsa ve cerrahi olmayan yöntemlerle sonuç alınamadıysa, dorsal kapsülotomi, eklem debridmanı ve sinoviyektomi ile tedavi uygulanabilir. Ancak şunu da belirtmek gerekir ki, bu evrede hastaya ulaşmak çok az rastlanılan bir durumdur ve çoğunlukla sinovite erken evre deformite ve eklem dorsosubluksasyonu eşlik eder ve beraber tedavisi gerekir.

Hafif ve orta derece subluksasyon: ilk bakışta hastada subluksasyon görülmese de, eğer hastaya MTF eklem Lachmann testi veya Şok test de denilen dorsale luksasyon provokasyon testi uygulanırsa dinamik instabilite saptanabilir. İzole dorsale doğru instabilitenin birincil sorumlusu olarak son yayınlarda plantar plate gösterilmektedir. Plantar plate patolojileri son olarak Coughlin tarafından evrelere ayrılmış ve evrelere göre yeni cerrahi tedavi yöntemleri tanımlanıp uygulanmaya başlanmıştır. Bu yöntemlerin en yenisinde omuzdaki artroskopik el aletlerinin daha küçük ölçekte sunulduğu ve Weil osteotomisi ile beraber direkt plantar plate tamiri tekniği geliştirilmiştir. Bu yöntem şu anda özellikle Amerika'da çok popülerdir.

Cerrahi tedavi kişiye özel planlanmalıdır. Öncelikle dorsal yaklaşımla kontrakte olan yapılar sırasıyla gevşetilir. Dorsal kapsülotomi ile başlanır, gerekirse ekstansör tendona Z uzatma uygulanır. Sonrasında kollateral bağ gevşetmesi uygulanır ve gerekirse koronal instabilite varlığına göre kollateral dengeleme uygulanır (lateral veya mediyal kollateral sıkılaştırma yapılır). Buna rağmen instabilite devam ediyorsa fleksörden ekstansöre tendon transferi uygulanır.

İleri subluksasyon ve çıkık: İleri evrelerde, yukarıda anlatıldığı üzere, yumuşak doku gevşetme teknikleri uygulanır. Buna rağmen bu gevşetmeler sonrasında deformitenin düzelmediği görülebilir, bu durum özellikle metatarsın diğerlerine göre daha uzun olduğu durumlarda ortaya çıkar. Bu durumda ek olarak metatars kısaltıcı bir osteotomi tekniği (Weil osteotomisi vb.) kullanılarak anatomik metatars parabol dizilimi yakalanmaya çalışılır. Eğer buna rağmen dorsale subluksasyon devam ediyorsa fleksörden ekstansöre tendon transferi eklenir (Şekil 5. a, b, c ve d).

Bazı cerrahlar metatars başı rezeksiyonu yapılmasını önermektedirler. Ancak bu teknik ile transfer metatarsalji çok sık görülebildiğinden çok dikkatli olmak gerekir. Bununla beraber aşırı yumuşak doku gevşetme sonrası metatars başında avasküler nekroz görülebileceği için ileri olgularda kemik ameliyatının daha erken bir aşamada yapılması ve gerekirse ek yumuşak gevşetmenin daha sonra eklenmesi bu komplikasyondan korunmayı sağlayabilir.

Üst üste binmiş parmak: Bu evrede ileri subluksasyon veya dislokasyona ek olarak lateral kapsül yetersizliği de mevcuttur. Eğer hastada ek olarak 2. parmak anatomik lokasyonunu sınırlayan HV gibi ek bir patoloji varsa öncelikle 2. parmağın oturabileceği yeri açmak için bu sorunun çözülmesi gereklidir. Eğer hastanın HV nedeni ile ağrısı mevcutsa HV klasik yöntemler ile düzeltilmelidir. Eğer hastanın başparmak veya bunion ağrısı yok ise sadece yer açma amaçlı Akin proksimal falanks osteotomisi uygulanır. Yukarıdaki cerrahi metodlara ek olarak aşağıdaki işlemler uygulanabilir:

- Son evrede parmakta bir mediyale deviyasyon (koronal instabilite) varsa, öncelikle mediyal gevşetmeye ek olarak lateral kapsüler sıkılaştırma uygulanır.

- Bu yeterli olmaz ise minisütür çapa kullanılarak lateral kollateral rekonstrüksiyon uygulanır (Şekil 6).

- Yine yeterli düzelme yoksa, başparmaktakine benzer ancak ters kamalı proksimal falanks kapalı kama Akinette osteotomisi uygulanabilir. Bu yalancı bir düzeltme sağlar.

- Eğer bunlara rağmen koronal instabiliteden kuşkulanılıyorsa EDB tendonuna yeniden yön verilmesi (rerouting) yöntemi uygulanarak dinamik bir stabilizasyon sağlanmaya çalışılır. Bu yöntemde EDB, MTF eklemin 3-4 cm proksimalinden kesilir. Distalde kalan uç lateralde intermetatarsal bağ plantarından geçirilerek proksimal uca dikilir.

\section{Bunionet}

Beşinci metatars başında ağrılı şişlik ve çıkıntı oluşumu olarak tanımlayabileceğimiz bunionet deformitesi bazı yazarlar tarafından beşinci parmağın HV'si olarak da tanımlanmıştır. Tarihsel adlandırmada sıklıkla terzilerin bacaklarını çaprazlayarak oturmaları sırasında beşinci metatars başına lateraline gelen aşırı yük binmesi sonucu geliştiği için terzi çıkıntısı (bunion) olarak da adlandırılagelmiştir.

Her ne kadar yukarıda bahsedildiği üzere veya günümüzde yanlış ve dar ayakkabı giyimi sonucunda bu bölgeye binen aşırı yük esas etiyolojik neden olarak sayıldıysa da, hastanın anatomik metatars şekil bozukluğu da ek etiyolojik etmenler arasındadır.

Bunun yanında doğuştan gelen anatomik farklılıklar da bu oluşumu tetikleyebilir. Fizyolojik olarak 4. ve 5. metatarslar arasındaki açı ortalama 6,2 derece, 5 . parmak MTF eklem açısı ise 10,2 derecedir. Radyolojik verilere göre üç tip bunionet tanımlanabilir:

- Tip 1: Bahsedilen açılarda değişiklik olamadan 5. metatars başında çıkıntı gelişmesi (Şekil 7a). 


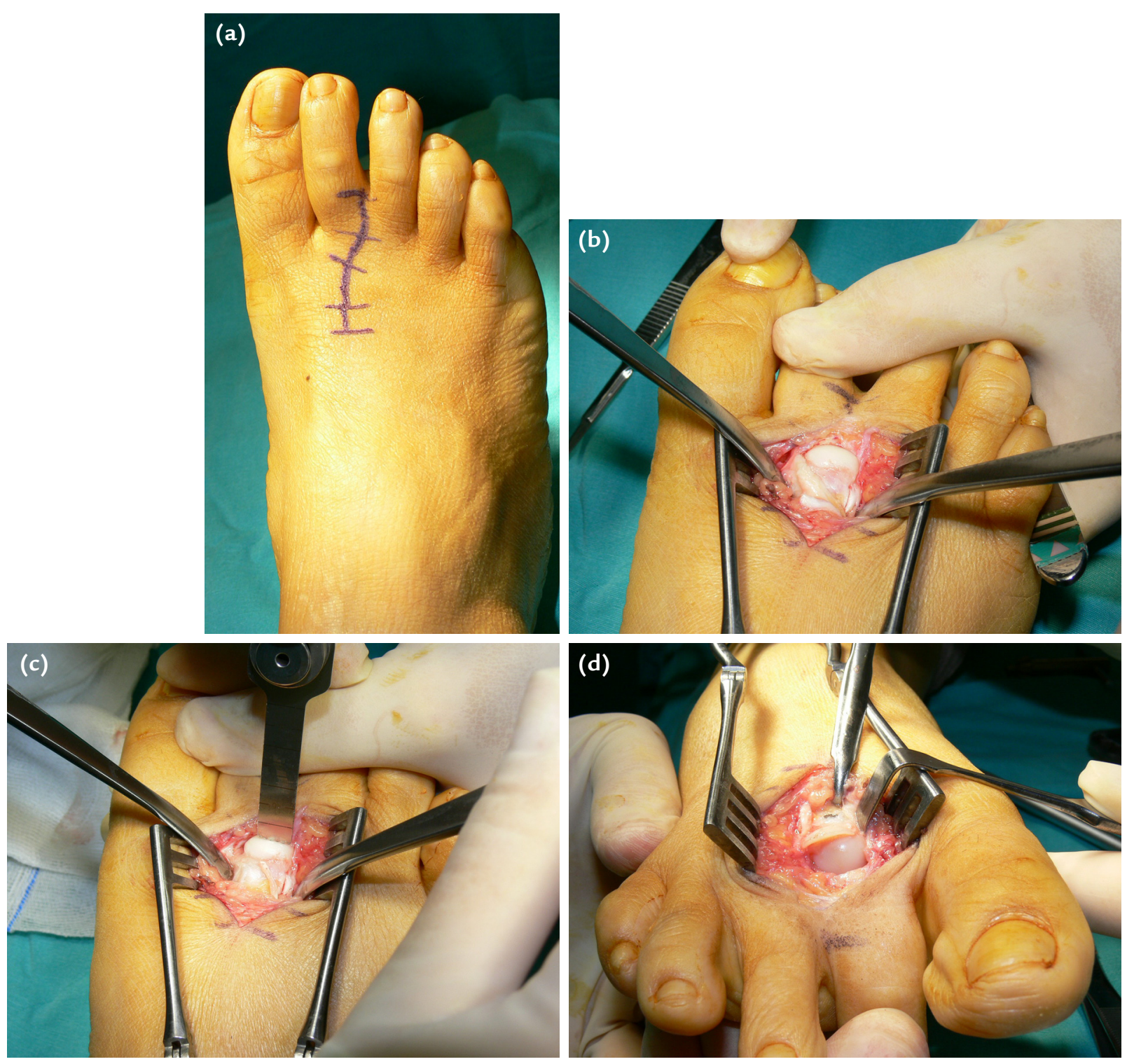

Şekil 5. a-d. Şekil 3'te görülen hastaya uygulanan Weil osteotomisi görüntüleri. Görüldüğü üzere osteotomi intraartiküler başlar ve ortalama 2-4 mm arasında bir kısalma sağlanır. En dikkat edilmesi gereken şey kesiyi olabildiğince ayak tabanına paralel yapmak ve kısaltma sonrasında metatarsın plantara yaptığı basıncı arttırmamaktır.

- Tip 2: Beşinci metatarsın distalde laterale yaylanmasının artması ile beraber görülen intermetatarsal açı artışı ile karakterize bunionet deformitesi (Şekil 7b).

- Tip 3: Fizyolojik olarak aşırı intermetatarsal açı ile karakterize deformite oluşumu (Şekil 7c).

Tip 1

Metatars başının büyük olduğu veya lateralde eksositoz olduğu durumlarda lateral eksostektomi uygulanır. Ancak hastada Tip 2 veya 3 bunionet deformitesi varsa bu operasyon hastayı rahatlatmayıp kalıcı ağrıya sebep olabilir.

\section{Tip 2 ve Tip 3}

Metatars başının laterale doğru açı yapması veya intermetatarsal açının fazla olduğu durumlarda intermetatarsal açılaşma fazla değilse distal metatarsal osteotomiler (Chevron veya rotasyonel oblik) yardımı ile çözüm bulunabilir. Eğer intermetatarsal açı çok fazla ise osteotomiyi proksimale kaydırıp orta şaft veya basisten bir döndürücü osteotomi yapma gereği ortaya çıkabilir. Metatars şaftının kanlanmasının çok iyi olmadığı düşünülürse, kaynamama riskini azaltmak için mümkün olduğunca bu osteotomilerden kaçınmak uygun olacaktır. 


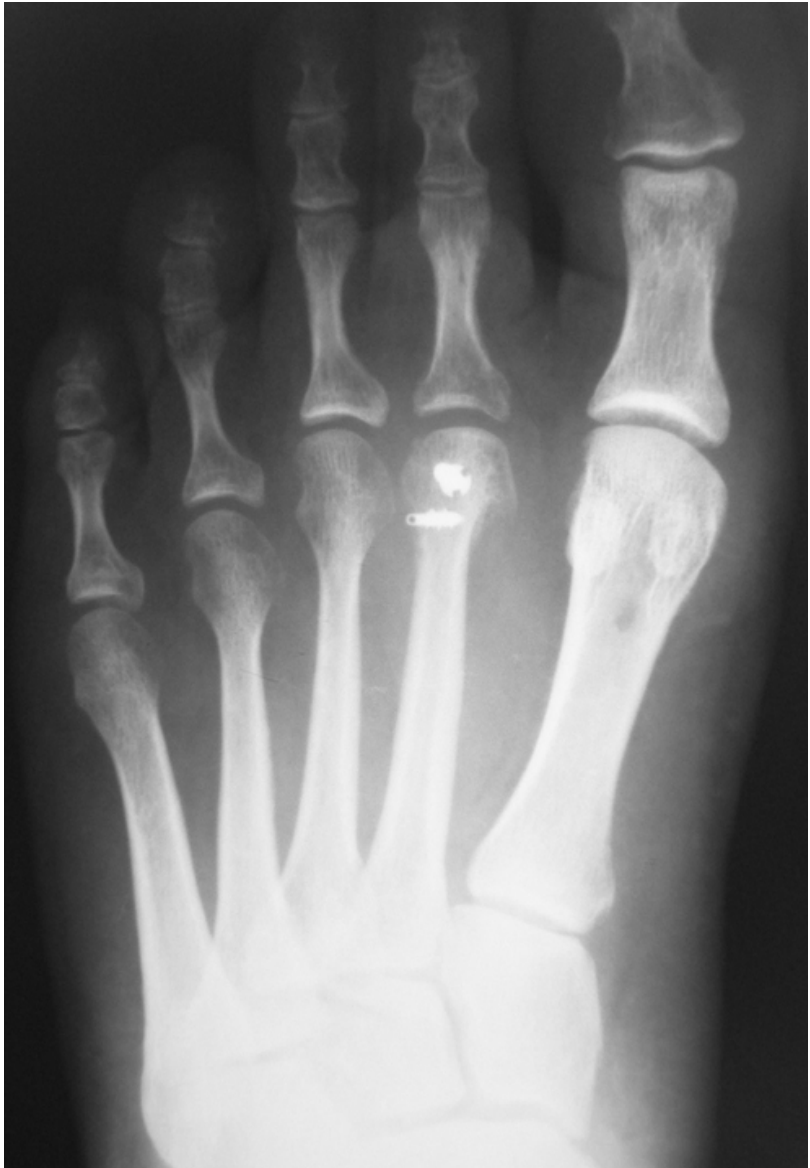

Şekil 6. Şekil 3'te görülen hastanın ameliyat sonrası grafisi. Görüldüğü üzere Weil osteotomisi yardımı ile MTF eklemdeki basınç dengelenmiş ve kalan koronal plandaki deviyasyonu düzeltmek amacı ile minisütür çapa kullanılarak lateral kollateral bağ rekonstrüksiyonu uygulanmıştır.
Yazar Görüşü: HV'de de olduğu üzere, bunionet hastalarının esas şikayeti distaldeki çıkıntı üzerindeki ağrıdır. Bu nedenle soruna odaklanıp radyolojik olarak mükemmel bir sonuç yerine, hastanın ağrısını azaltmak için, yazar tüm Tip 2 ve 3 hastalarında distal osteotomi metodunu seçmiş ve uygulamaktadır. Bu bölgede yapılacak bir Chevron osteotomisi ile çok iyi sonuçlar elde edilebilir. Yazar Tip 1 hastalarda bile bu metodun uygulanmasını önermektedir; çünkü hastalar bu metod ile ayak genişliklerinin daralması sonucu daha rahat ayakkabı giyebilmektedirler (Şekil 8a ve 8b).

\section{Parmak nasırları (Corns)}

Nasırlar vücudun koruma mekanizmasını işleterek fazla basınç alan noktaları üzerinde hiperkerototik tabaka oluşması ile meydana gelirler. Daha sık olarak görülen sorunlar sert nasırlardır ve ayakta sıklıkla metatars başlarının plantarında, parmak iP eklem dorsalinde ve dorsolateralinde veya beşinci parmağa özel olmak üzere falanks lateralinde görülür. Parmak arası gibi masere olmaya uygun bölgelerde ise yumuşak nasır oluşumu söz konusudur. Her iki nasır oluşumunda da kötü ayakkabı giyimi baş nedendir. Bunların dışında hastada hiperkeratoza meyilli bir dermatolojik hastalık varsa ayağın değişik bögelerinde nasır görülmesi doğaldır.

Yumuşak nasır oluşumunda parmak arasındaki falanks kenar kemik çıkıntılarının (egzositozların) önemi büyüktür. Bu derlemenin yazarının görüşü olarak, parmaklarında kemik üstü et dokusu fazla olan kişilerde klinikte yumuşak nasır daha az sıklıkla görülmektedir. Yumuşak nasırlar en sık 4. parmak aralığında, sert nasırlar ise en çok 5. parmak dorsolateralinde görülür. (a)

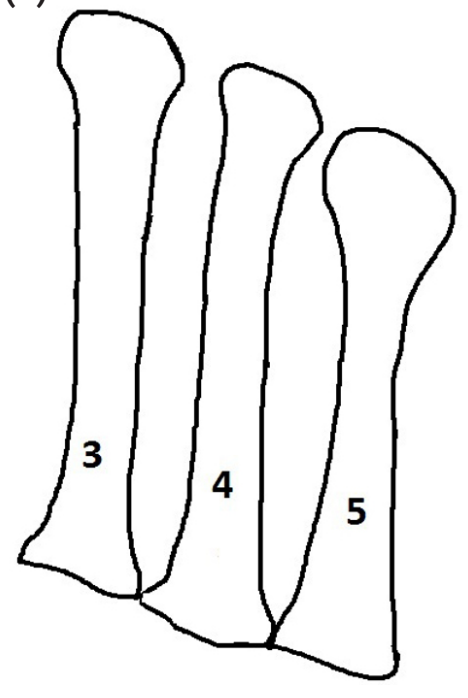

(b)

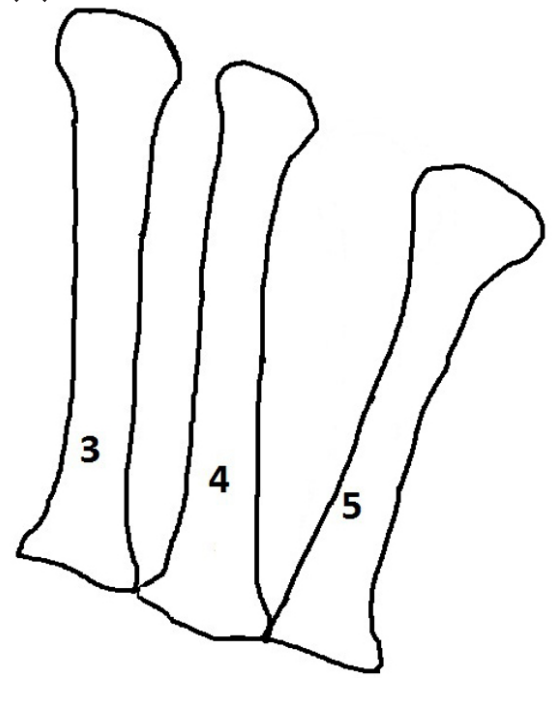

(c)

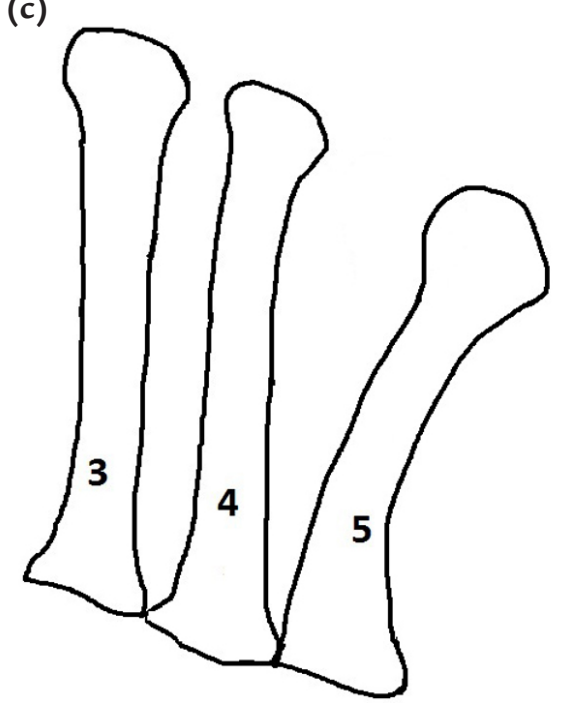

Şekil 7. a-c. Tip 1 bunionet deformitesi (a). Tip 2 bunionet deformitesi (b). Tip 3 bunionet deformitesi (c). 


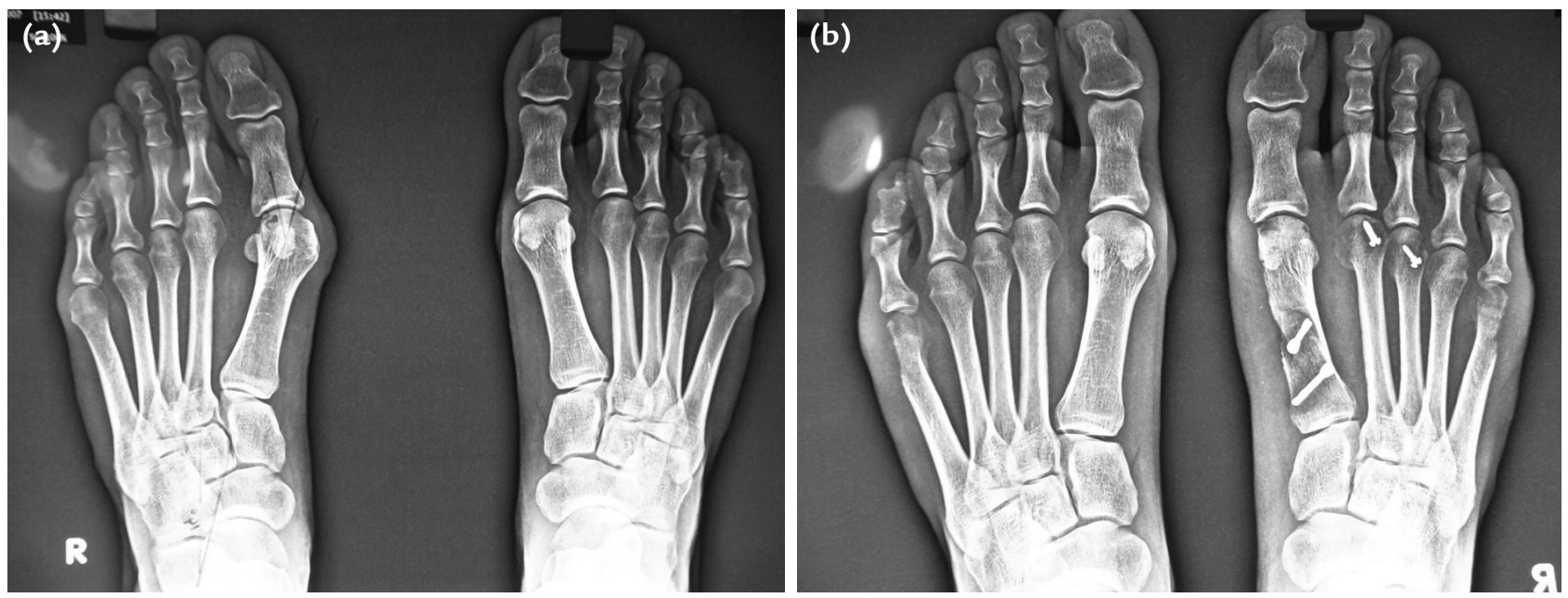

Şekil 8. a, b. Sağda HV ve 2 ve 3. metatarsaljisi ve bilateral bunionet deformitesi olan olgunun ameliyat öncesi ve sonrası grafileri. HV Luddloff proksimal oblik osteotomisi ile düzeltilmiş, metatarsalji için 2 ve 3. metatarsa Weil kısaltma osteotomisi uygulanmış ve bunionet düzeltmesi için de bilateral Chevron osteotomisi uygulanmıştır.
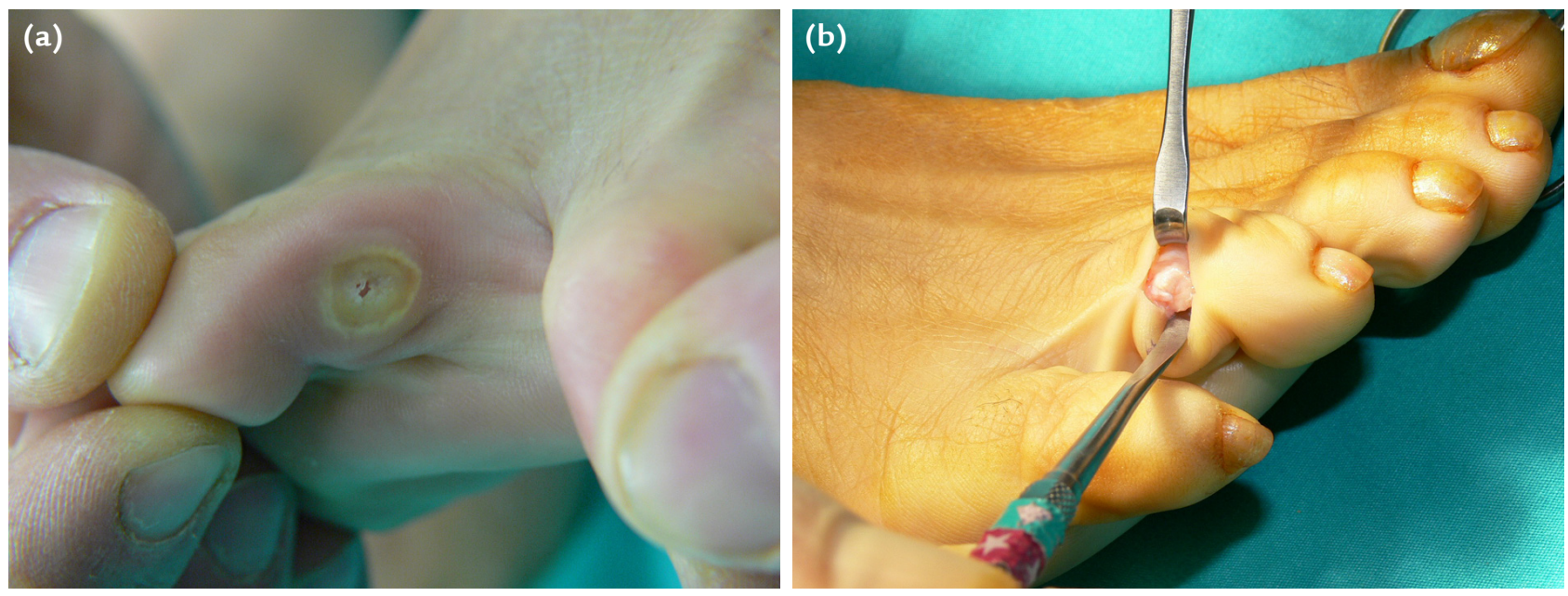

Şekil 9. a, b. Dördüncü Web aralığında yumuşak nasır olgusu. Nasırı oluşturan lateral kondilin ameliyat esnasındaki görünümü sunulmaktadır (b).

Sert nasırlar: Cerrahi olmayan tedaviye yanıt vermeyen kişilerde yapılacak bir lateral veya dorsolateral kondilektomi ile çok başarılı sonuçlar elde edilebilir.

Yumuşak nasırlar: Sert nasırlara benzer olarak bu nasırlar içinde cerrahi tedavi metodu lateral kondilektomidir. Burada unutulmaması gereken, bazı ileri durumlarda nasırın olduğu bölge kadar nasır oluşmasını sağlayan karşı parmaktaki lateralkondilin de alınması gerekliliğidir. ileride oluşabilecek nebde dokusundan kaçınmak amacı ile kesinin nasır dorsalinden yapılması gereklidir (Şekil 9. a, b).

\section{KAYNAKLAR}

1. Aydogan U, Easley M. Lesser Toe Deformities and Bunionettes. In: Foot and Ankle: Orthopaedic Surgery Essentials. Thordarson DB, editor. 2nd ed. Wolters Kluwer Health, Lippincot Williams \& Wilkins; 2013. p.144-74.

2. Nery C, Coughlin MJ, Baumfeld D, Mann TS. Lesser metatarsophalangial joint instability: prospective evaluation and repair of plantar plate and capsular insufficiency. Foot Ankle Int 2012;33(4):301-11. CrossRef

3. Kelikian AS, editor. Sarrafian's Anatomy of the Foot and Ankle. 3rd ed. Wolters Kluwer Health, Lippincott Williams \& Wilkins; 2011. 